\section{A LECTURE}$$
\text { ON THE }
$$

\section{USE OF THE MICROPHONE IN SOUNDING FOR STONE.}

\section{Delivered in University College Hospital, Lonitin, Tuesday, Fune 4 the 1878 .}

BY SIR HENRY THOMPSON, F.R.C.S., M.B., Suryeon-Extraordinary to His Majesty the King of the Delgians; Consulting Surgeon to the Hospital.

Gentlemen, - My object to-day is to show, as far as I can, how the microphone, a very recent invention of Professor Hughes, may be applied to the operation of sounding for stone. But, in order to make myself perfectly clear to you, it will be necessary at the outset to define one single term, otherwise there is a chance of what I say being misunderstood. I mean the word "sound". This word, as we know, has a technical sense, and signifies the instrument lying before me, the sound ; and the verb that arises from it is "to sound"-to sound in the bladder. But the word is also used to represent an acoustical phenomenon, that is the note produced by striking the sound against another body. If I strike this table, I am said to make a sound; but that is precisely the term that I will not use ; because, to get into such a sentence as this, "I am going to use that sound to sound a patient, and please listen to that sound", might lead to confusion. Instead, therefore, of speaking of sound, I shall use the word "note" as being the best substitute I can get. If I use the term sound at all, I shall mean this instrument or the manner of using it ; when I want to speal of the effect produced, I shall ask you to listen to the note.

Having made that preliminary remark, I have a word or two to say about sounding for stone, independently of the apparatus that is before us. Let me ask you to go back some fifty years - which none of you, however, can do, but which down here some of us are able to do. Forty-five or fifty years ago, sounding for stone was a totally different operation from that which it is to-day; and in my opinion that fact is not half enough appreciated by the profession either here or anywhere else. We have traditional notions of sounding for stone; and if we sound at all with the same intention or in the same manner as our forefathers did, and if we adapt their mode to the exigencies of the present day, we shall meet with nothing but failure. I go further still, and say this, that you might as well compare the famous old Brown Bess with the rifle of precision of the present day, as compare the sounding of 1828 with that of the year 1878 .

You will remember that at the time of which I speak there was but one operation for stone. Whether the stone was large or small, there was but one mode in which it could be removed from the human body, and that was cutting-lithotomy as it is generally termed. It mattered little what the size of the stone was, within certain limits. The size of the incision would not vary greatly. A certain incision-dangerous at certain ages, without doubt-had to be made; and whether that were a quarter of an inch or half-an-inch bigger one way or another was not a matter of very great importance. Hence, it was not then a matter of high import that you should discover the stone when it was small. Indeed, it was a common thing in those days for the stone not to be thought of when it was small, and it only came under surgical cognisance when it was large. No one liked to do a great operation to remove a thing about as big as an apple- or orange-pip; and it was common for the surgeon to say (more, however, on the Continent than here), "You have symptoms of stone it is true, but I think it is not ripe for an operation ; go away, and come again in a year or two". Patients were thus absolutely put off from month to month, and sometimes from year to year, until the stone should be sufficiently "ripe" for the operation. No one liked to perform an operation unless the stone was nearly of the size of a chestnut. The problem of to day is an entirely different one We now have two modes of operating : one of them, as you know, by crushing, in addition to the older one by cutting. The element of success in the operation of crushing is that you should get the stone early, that you should find it small, and then you may make almost absolutely certain of a successful and safe operation. The large stone, as before, will be remitted to the cutting operation, but one may have a much more successful operation in crushing, provided the stone is small. The end of all our endeavours ought to be find the stone as small as possible and remove it in that condition. But that is not the whole problem.
Were it only so, you would see that a much more delicate aperation of sounding is required than heretofore; but, inasmuch as the operation of crushing, however small the stone, means making it into fragments smaller still, you will see that it is necessary not only to be able to recognise the small stone by sounding, but also to recognise small fragments of the stone. It is alleged against lithotrity that, if you leave a small fragment behind after the operation is over, or presumed to be over, that small fragment may become the nucleus of a larger stone hereafter, and you are not only not benefiting your patient, but you have laid a train for more serious mischief. Thus it is that $I$ have all along said that, if lithotrity be not equal to removing the least fragment which otherwise might be a trouble, it is not an operation to be ad. mitted into the domain of surgery. I would rather cut every case that came to me-I mean with a view to success-than cut only some, and do lithotrity badly for the others.

There is no perfect lithotrity, there is no lithotrity worth your notice or mine, unless it can make absolutely sure of removing every fragment from the bladder. Now, you may say, in view of this which I have before me : "Is it not the case that lithotrity is equal to that at the present moment? If it be not, why is it that it has stood so high as an operation?" Well, I say, it is equal to it. What I have to show you here is something which will supplement our present power ; but, I say it with the greatest confidence, the result of our present power with regard to lithotrity is, that we are able to remove to the last fragment with unerring certainty, provided the bands in which the case is are fairly (and only fairly) practised. I have demonstrated over and over again, both here and in hospitals abroad, the power of our present instruments to remove the smallest possible fragment. I have, over and over again, obtained an audible note from a piece no larger than a split pea, removing it afterwards to show the truth of the affirmation. You may say : "What more can you want than that?" Well, I think, not much ; but let me confess that that is not at present an unireasally received opinion. There are many persons who still bring alkegations against lithotrity, saying : "It is all very well; you may happen to do this, but it does not lie within the usual practice of surgery to be so certain about that." It is still thought that it is 2 very easy thing to leave a piece behind. At all events, we will grant this, and we will grant still more, that if we can get anything which will make our task more easy, more simple or certain, it is our duty to add it to our present powers; and I think you will find that we have that in the apparatus. before us.

But before showing you what the power of the apparatus is, I wish it to be most distinctly understood that this is not an instrument which is in variably to be used-no, not in more than onecase out of twentsy. Please understand that the stone is to be found by the ordinary metrod; and this is, I certainly will not say a surgical or scientific toy, a resource which we have in reserve for exceptional and difficult cases, or for throse who may find it perbaps more usefal than their unassisted hands and ears. It may be compared to a very high power in the microscope. I need not tell you what great discoveries have been made with the microscope, in every direction throughout nature, with very low object glasses-glasses not to be mentioned in comparison with the high powers which we now use. It is a question how much those extremely high powers have done. They have really done very little. We have at present our fourth, our fifth, and our eighth, within the reach of ordinarily good microscopists; but, when you come to the twelfth and the sixteenth, they can only be used by highly skilled persons, and only bere and there can such extremely high powers be required.

Now, the analogy between the microscope and the microphone is very strong. There are many things which we have been in the habit of regarding as without sound, as not producing a note. Nobody, for example, has ever heard a fly walking upon a window-pane. Most persons would say it was noiseless; but it is not so. It simply prodaces a noise which our unaided ears cannot appreciate. We cut our finger, and we see a little blood. The ordinary eye sees nothing but a little red fluid ; nine persons out of ten would be astonished at seeing, under the microscope, what a composite fluid it is-the corpuscles, the liquor, and so on. Just so there are many notes in nature of which we have not the slightest appreciation, but by Professor Hughes's ad. mirable invention we can hear and measure them.

With these observations, and wishing you to understand clearly the place in which I should put this relatively to our surgical armamentarium, I will show you what the microphore is. Here is a battery, with the smallest section employed. If we had used a large section, it would have interfered with the success of the experiment. The cuorent goes up to a telephone, then comes back here, and then goes on to another telephone. It is to be united with the sound, then with this wire, which goes to the other pole of the battery. It does nat matter whether you begin with the positive or the negative. 
I have here an ordinary sound for sounding a bladder and a microphone upon it. You see a little piece of gas-carbon balanced with a spring, and another piece lying transversely to it. Now, by striking anything with the point of the sound, an acoustic wave goes through the particles of the steel sound and comes up to this piece of carbon. This movable piece receives the impulse, and this now comes into circuit. But it is no longer an acoustic wave ; it is transmuted into an electric wave. It suffices to touch a pin; the wave goes up; molecular changes take place which are acoustic in that piece of carbon, and there it ceases ; they are then transmuted into electrical waves and are made audible by means of the telephone. Here is the secret of the matter : that, however tiny an acoustic wave is, it may be magnified the instant it becomes an electric wave. I connect these two poles, and, if I rub the two ends of the pieces of wire together, you can distinctly hear the sound by means of the telephone. (Experiment.) The circuit is now complete. I have here an extemporised bladder (a basin lined with wash-leather), and I put in it a small calculus. We will suppose that there is some suspicion that a portion of a stone is in the bladder, or a small fragment left in it. You may push it perhaps, but you cannot feel anything ; but, with this instrument, if you touch with your sound a fragment, however small, your telephone will at once speak. I have used the instrument in the bladder, but, unfortunately, I have not a patient here to-day. If I touch but the point of a pin or a finger-nail, the sound is distinctly heard. Some trouble is required in order to get the microphone right for our purpose. In this respect, it is like the aneroid. If you want to measure certain heights with an aneroid-if you want to measure from the sea-level up to five thousand feet-you have one instrument for that purpose, and then for a second five thousand feet you require another instrument. One aneroid will not suffice for the whole range in the case of Mont Blanc, for instance, which is fifteen thousand feet; there you would require a mercurial barometer. The aneroid has only a certain limit within which it is correct. So it is with the microphone. I could put a microphone on this circuit which would be utterly useless. The microphone I have shown you would not enable you to hear the march of a fly. Professor Hughes says that he could make the march of a fly across a piece of net sound like the tramp of an elephant. I have heard a fly walk across a piece of net, with a very audible note. In a public exhibition of the instrument, with an audience, say, of one thousand or one thousand two hundred persons, a large telephone is used - a round trumpet-shaped thing that conducts the notes to the audience. Now, all that is very well in an ordinary lecture, but it is of no use in operating for stone. What I want to show you here is the way in which the instrument may be used in the chamber or hospital-ward. But, as I have said, this.instrument is not delicate enough to make the march of a fly audible. If it were, when you put it into the bladder, you would have such a noise from friction from the urethra and bladder that you would not hear the little bit of stone. This is an illustration of the difficulty that often attends the use of delicate scientific things when you come to actual practice. This seems very simple when it is all arranged before you, but it has required some hours' trouble to get it right.

I have an instrument here which is fine enough and delicate enough to hear the sound of a fly ; but, if the point of the sound were merely struck against the bladder, it would give a metallic note, just as if it had struck against a stone, so very sensitive is it. It must be borne in mind that you do not get a different note from the different bodies struck. The electric wave merely multiplies or magnifies the wave in the steel instrument; but it does not matter whether you have struck a blanket or a flint, or the mucous membrane of a bladder or a stone the sound is precisely the same. (Experiment.) Here, if you have too powerful a battery, the friction-sounds would be augmented, and you will not succeed in your effort. Even the echoes of the room may interfere with your operation. I will now put the sound in the extemporised bladder, and, as I touch the little fragment of stone, you will hear a sharp click. It is in dirty thick water, and I cannot tell mrself when I strike it; but those of you who listen through the telephone will perceive it.

In a few words, then, the demonstration is this : that you can make absolutely logically certain the existence of small fragments in the bladder, for the detection of which you have hitherto depended upon your unassisted ear and hand. I want particularly to say that the unassisted ear and hand will suffice for almost all cases. There may be one in twenty cases in which it may be necessary or desirable to use this instrument. It is something like the case of the endoscope in regard to the urethra. When it was first introduced, a good deal was said about its being applicable to all disorders of the urethra and the bladder; but it was found in practice that, however well it looked upon paper, there was only a case here and there that might be benefited by its use. What has mainly actuated me in bringing this subject before you is this. It is obvious that this new invention, which increases the sound of a foreign body, is equally applicable to a bullet or a shot, or any foreign body at the bottom of a wound or a piece of diseased bone. I thought it was desirable that this power should be examined carefully by one who was in the habit of doing something in this way, and it occurred to me that it would be agreeable to yourselves, and certainly gratifying to my own feeling, that the utilisation of the powers of this new invention should be first shown, not at Paris, not at Vienna, but in London, and, best of all, at our own Alma Mater.

I am indebted to Professer Hughes's kindness and courtesy for the microphones which I have exhibited, and for his aid and counsel in the matter.

\section{OBSTETRIC MEMORANDA.}

\section{CASE OF TWINS AND SPONTANEOUS EVOLUTION.}

I wAS requested to attend Mrs. S., aged 24, during her confinement. This was her fifth pregnancy. On arrival, I was informed that the pains were frequent and of a bearing down character, and, on examination per vaginam, I found the head presenting in what is known as the fourth position; that is, the long diameter of the head occupies the left oblique diameter of the pelvis ; here the forehead is close to the right foramen ovale, while the occiput is directed to the left sacro-iliac synchondrosis; the anterior fontanelle is directed to the former, the posterior to the latter. As the case progressed, the occiput turned into the hollow of the sacrum, and the forehead was directed to the symphysis pubis, and eventually it emerged under the pubic arch, followed by the eyes, nose, mouth, and chin. On the birth of the head, the cord was found coiled once round the neck; while I was drawing it down and hooking it over the head, the uterus acted strongly, and the child was born. After tying the cord and waiting for a few seconds, I made a vaginal examination, and found the placenta in the vagina, and by its side the left arm of a second child. The uterus was acting so strongly and continuously that the membranes were ruptured, the placentæ, which appeared to have a vascular connection with each other, were expelled, and the child was jammed down into the pelvis, so that it became impossible to turn. The pelvis being roomy, and believing the child to be small, and seeing that the thorax was well down in the hollow of the sacrum and the axilla, almost on a level with the lower edge of the pubes, the pains being strong, I thought it best to leave the case to nature, and was not disappointed ; for the thorax became lower at each pain, followed by the side of the abdomen, and, lastly, the pelvis and lower extremities, the arm and shoulder remaining fixed all the time. On slight traction being made with the fingers hooked over the shoulders, the head soon followed, and the second child was born just thirty minutes after the birth of the first. Both were girls; the first lived, but the second, I need hardly say, was dead. This was, no doubt, due to the separation and extrusion of the placentæ prior to the birth. The principal points in this case were, first, the rather unusual presentation of the head of the first child, and its being born with the face towards the pubes; secondly, the rapid expulsion of both placentæ prior to the birth of the second child; and, lastly, the very rare position of the second child, which might be placed in the list of cases under the name of spontaneous evolution.

\section{David S. BRADley, M.D., Chesterfield.}

\section{PLACENTA RETAINED ONE HUNDRED AND TWENTY- THREE DAYS AFTER MISCARRIAGE.}

Mrs. P. miscarried on December 3 rd, 1867 , when a three months fotus was expelled. The placenta could not be removed. There was a continual, thin, sometimes pale, often very red discharge, with occasional little clots of blood. On April 2nd, 1868, I found a globular mass presenting at the os uteri; the os dilated to the size of a flurin. I could not grasp the presenting body, but managed to rotate it with the finger. This seemed to loosen it. I gave ergot in fifteen-grain doses of the powder. After taking the ergot for twenty-eight hours, the placenta came away. It weighed about three ounces; its fotal surface was folded on itself. The mass was a pointed oval ; the maternal surface pale straw-colour; the substance more dense than the ordinary placenta. There were no signs of putrefaction whatever. This case, like those in the JOURNAL of the 4th and 18 th ult., has some interest, I think, especially in a medico-legal sense ; and therefore I send it to be in company with the previous cases.

Frederick W. P. Jago, M.B.Lond., Plymouth. 